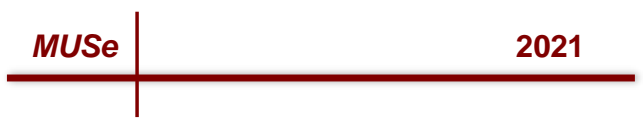

\title{
Apple iPhone: A Market Case Study
}

\section{Daylin Van De Vliert}

\begin{abstract}
Founded in 1976, Apple inc. quickly became one of the biggest companies in the world.

Throughout the years, Apple has been a part of the technology market, where there has been an exponential number of opportunities and threats. This market case study aims to determine how Apple can target such opportunities to help predict future trends and influences over the market. To identify these trends and market influences, I have first conducted an environmental scan of Apple's current and future market(s). Then I described Apple's fundamental psychological and sociocultural consumer behaviors. Finally, I identified Apple's target market, how they have chosen to segment, and the demographics and geographics within Apple's largest target segments. As a result of successfully identifying trends in the past, Apple continues to impress with its globally known brand name and customer base/market; however, Apple must continue to identify future opportunities to stay relevant in the ever-advancing technological market. This analysis of the marketing context suggests Apple may need to reposition its iPhones to maintain its leading position in the marketplace.
\end{abstract}

\section{Introduction}

The technology giant that has cornered the market on all electronic types, ranging from computers to phones to tablets: yes, I am talking about Apple. Founded in 1976 in California, United States, Apple has become one of the most well-known companies that exist to date. In 1976 the Apple I, the first computer built by Apple, had a significant influence over the public. Additionally, the following are some of Apple's most influential products (Gibbs, 2018):

- Apple I (1976)

- Macintosh (1984)

- iMac G3 (1988)

- iPod (2001)

- iPhone (2007)

- $\quad$ iPad (2010)

Apple uses product-based grouping that divides its products into "services, Mac, iPhone, iPad, and other" to help distinguish revenues and profits from their various high-selling products (Dudovskiy, 2021, para 5). In addition to Apple's hierarchical organizational structure that motivates employees to perform well through promotion opportunities, Apple has developed a vast and ever-increasing consumer base.

In 2007, with the idea to combine a cellphone, digital camera, and computer onto one small handheld device, Apple introduced the iPhone. It has been deemed that the story of the 


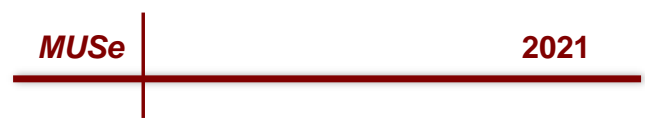

iPhone is "one of evolution, not revolution" as each year, Apple makes the phones bigger, faster, and exponentially more popular (Pierce, 2018, para. 10). The iPhone is Apple's bestselling product, with more than 46.89 million units sold in the fourth quarter of 2018 alone (Statista, 2021)! Furthermore, operations for Apple's iPhone have already become carbon neutral. To further its environmental consciousness, Apple have made commitments for its supply chain and products to demonstrate carbon neutrality by 2030 .

By utilizing multiple marketing strategies discussed in this analysis, you will begin to see how Apple has marketed the iPhone to help them position themselves in the market today.

\section{Environmental Scan}

As the world continues to develop, many factors will impact the way Apple iPhones are marketed. These factors are economic, social, regulatory, competitive, and technological. By interpreting potential trends, Apple can use market information to identify opportunities for profitable growth. The above trends for this business are discussed briefly as follows.

\section{Economic Factors}

First, economic factors that will impact Apple and its marketing activities. The most significant external economic factors for Apple are as follows (Lombardo, 2019, para. 7):

1. The stable economies of developed countries (opportunity)

2. The rapid growth of developing countries (opportunity)

3. The rising level of disposable income among Apple's target customers (opportunity)

Arguably, the most significant economic factor for Apple to consider is the rapid growth of developing countries. Take Bolivia, for example; the high economic growth rate creates numerous opportunities for Apple to increase revenues through sales in foreign markets. In these developing countries, cultural niches are important for Apple to find as they are the ultimate driver of sales and success. These cultural preferences can be met through simple software and content adjustments that make Apple products more appealing to the specified target (Laugesen \& Yuan, 2010). Furthermore, current financial stability in already developed countries creates additional opportunities for Apple to expand its markets. These developed countries have provided a stable base for Apple to grow their consumer market, as Apple's brand recognition has 'locked-in' millions of repeat buyers. These repeat buyers allow Apple to advance by pursuing new opportunities in the developing markets. Both these factors, alongside the increase of disposable income, consistently drive Apple's marketing opportunities and help them sell their relatively high-price products (Lombardo, 2019).

\section{Social Factors}

Second, social factors will impact Apple and its marketing activities. In Apple's case, the following social trends are significant in the macro-environment (Lombardo, 2019): 


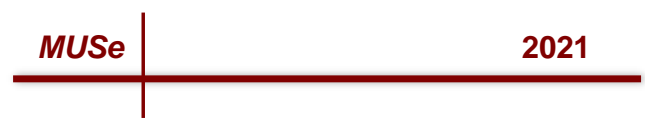

1. The increasing use of mobile devices and mobile access (opportunity)

2. Consumers becoming more dependant on digital systems (opportunity)

3. Global anti-Apple sentiments (threat)

The direct relationship between rising mobile access and the increase in Apple Inc.'s revenue is an opportunity. There is a constant increase in demand for mobile devices like Apple's iPhone that provide a simple-to-use hand-held device with worldwide communication and accessibility. Additionally, as technology advances and the population ever-increasingly becomes dependant on digital systems, Apple will continue to sell more of its products because of this higher demand. Since consumers are becoming more dependent on these systems, old advantages will become regulated and more common; thus, it is important that Apple continues to identify new factors that can continue to give them competitive advantage. Despite the previous opportunities, the company faces the social threat of opposition against business operations (Lombardo, 2019). Anti-Apple sentiments can drastically reduce brand image and customer loyalty. Regardless of the market, consumers are becoming more conscious as to what companies they are promoting and purchasing from. Currently, the trend is for consumers to support an eco-conscious business that also falls in-line with common societal and cultural norms.

\section{Regulatory factors}

Third, legal/regulatory factors, which might be the most important factor to consumers, will impact Apple's marketing strategies. In Apple's case, the following are the most significant eternal legal factors:

1. Increasing privacy regulations (opportunity and threat)

2. Legal challenges against apple's policies and practices (threat) (Lombardo, 2019, para. 19)

With consumers demanding more privacy and security, Apple has the opportunity to provide an innovative and effective solution to this upcoming problem. By interpreting this trend, Apple can further understand user preferences regarding what information is to be kept private. If Apple fails to do so, their customers may see them as unreliable and switch to more secure competitors. Controversially, as consumers' privacy and security demands increase, Apple faces issues and potential threats with its current policies and procedures. For example, according to BBC, French authorities awarded "DGCCRF (a French watchdog) \$1.23 billion USD for [Apples] anti-competitive behaviour," which demonstrates the consequences of legal challenges and not abiding by standard policies (David, 2020, para. 9). Although $\$ 1.23$ billion may not be a lot for a trillion-dollar company, there are also substantial threats to brand image and personality that could be devastating for Apple.

\section{Competitive factors}

Fourth, competitive factors that help drive Apple's marketing strategies are crucial, as they 


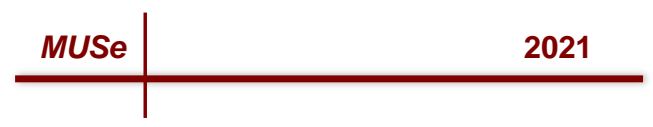

evaluate performance and can either pull in or push away potential customers. In Apple's case, the following are significant competitive factors (Maverick, 2021):

1. Low switching costs to competition (threat)

2. The large and increasing number of part suppliers (opportunity)

There is a high level of competition among major companies that compete directly with the iPhone. Companies such as Google, Samsung, and Huawei directly compete for Apple's consumers, as there is a relatively low switching cost. That is, there is little to no investment difference for a customer to buy a Samsung phone rather than an Apple iPhone. A low switching cost "strengthens consumers' bargaining power," making it crucial for Apple to consider (Maverick, 2021, para. 9). This is one area where Apple has excelled. By building up outstanding brand loyalty and a substantial consumer base, most customers would not consider any other smartphones on the market; however, Apple needs to keep building these consumer relations to continue to grow its consumer base.

All smartphones are comprised of various components produced by the company's supply chain. Today, numerous suppliers can satisfy Apple's supply chain needs. This is a massive opportunity, as the increasing number of suppliers weakens their bargaining force and strengthens Apple's position in negotiating with suppliers (Maverick, 2021).

\section{Technology factors}

Fifth, technology factors are the most vital for Apple as a company having a successful market strategy. Since Apple is currently one of the lead technological companies, they need to ensure that they capitalize on all technological trends. In Apple's case, the following are significant technological factors (Dang 2020):

1. Growing cloud computing demand (opportunity)

2. Growing technological capabilities of competition (threat)

As technology advances and the amount of information on the web increases, there comes a need to store said information. This opens an opportunity where Apple can take advantage of the growing demand for their cloud services. This increase in demand can be recognised when looking at Apple's statistics and seeing that "from a technology perspective, the future of mobile phones will be differentiated by software" (Laugesen \& Yuan, 2010, para. 16). In exploiting this software opportunity "on enhancing its cloud computing infrastructure," Apple can further maximize its profits (Dang, 2020, para. 8). The advancement of technological capabilities of their competition threatens Apple, as new competitors (or old competitors) can (re)enter the market, taking over more of Apple's market share. Thus, Apple needs to ensure that they are up to date on all technological advancements in addition to exploiting all foreseeable opportunities that will help to protect the business against these trends.

After discussing five of Apple's major environmental factors, what does the future hold for Apple? With the increasing competition in the cell phone market from brands such as Samsung and Huawei, the Apple iPhone is being challenged for its consumer base, market 


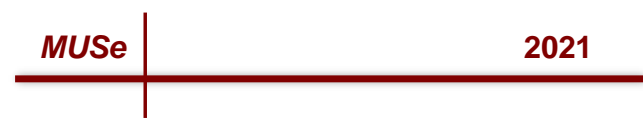

share, and lower price points. Additionally, with most consumers becoming more environmentally conscious, Apple has found an increasing number of customers choosing to switch brands or not buy new products altogether. The decrease in returning iPhone buyers is due to the hazardous chemicals and harmful mining practices used for software components; in response, Apple has announced that all its products will be carbon neutral by 2030 (David, 2020). By further identifying and pursuing buyer and supplier power, Apple may increase the barriers to entry in the smartphone market. To stay ahead of market competition from companies like Samsung and Huawei, Apple needs to exploit growing demands for cloud capabilities and other software advantages that will further differentiate Apple from strong competition.

\section{Consumer Behaviour}

The mental and social process that precedes and follows the actions a person takes when purchasing and using a product is known as consumer behaviour. Consumer behaviour helps marketers understand what influences consumers' buying decisions. Apple can use knowledge of consumer behaviour to fill the gap in the market and identify products that will fulfill consumers needs. The consumer purchasing decision process is made up of five steps:

- Problem recognition

- Information search

- Evaluation of alternatives

- Purchase decision

- Post-purchase behaviour

Firstly, problem recognition is the perception of a need in the eyes of a consumer. With Apple's iPhone, it is the need for a portable, yet powerful, device that allows the user to access information quickly and efficiently. Secondly, information searching is where Apple's colossal brand name helps their marketing. The company is most likely to be found in an internal search (one's previous knowledge) and through an external search (recommended through friends and family etc.). Thirdly, alternative evaluation is consumers assessment of the value of each brand they would consider. This evaluation is based on an individual set of evaluation criteria that one uses when considering acceptable solutions. Fourthly, the purchase decision is deciding when to buy and whom to buy from, typically influenced by incentives provided by the sellers when the product is purchased. Finally, consumers compare the product they purchased to their expectations, which is also known as consumer satisfaction or dissatisfaction with the product.

The five-step consumer purchasing process is influenced by the marketing mix, psychological, sociocultural, and situational influences. I will focus on psychological and sociocultural influences, as they tend to have the most involvement in influencing consumers when buying. 


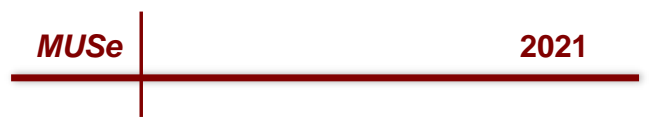

Psychological Influences

The following are the psychological factors that influence consumer buying behaviour as far as the iPhone is considered:

- Motivation

- Personality

- Perception

- Learning

- Values, beliefs, and attitude

- Lifestyle

In my opinion, the two most critical psychological influences regarding consumer behaviour that Apple should consider for marketing the iPhone are personality and lifestyle.

An individual's different traits, like compliance, dominance, and assertiveness, are all factors that play into one's personality. When a consumer purchases a product, one thing they consider is the self-image or self-concept. Self-image/concept is how a "consumer sees and feels about him/herself" and how "customers want others to see them" (Atkinson, 2018, paras. 4-5). Apple's well-known brand makes the iPhone look close to luxury in the eyes of consumers. These standards influence customers to buy the iPhone over alternatives because it gives consumers a sense of wealth and status. In other words, it helps the consumer turn their actual self into their ideal self. The personality of the individual is closely related to the lifestyle of the individual.

The lifestyle of an individual typically reflects an individual's attitude, view, and world view. Different lifestyles and modes of living have been grouped into target markets that play a significant role in a company's marketing strategy. Since Apple is such a big, well-known brand, they appeal to various lifestyles and can access a lot of target markets.

\section{Sociocultural Influences}

The following are the sociocultural that influence consumer buying behaviour as far as the iPhone is considered:

- Personal influence

- Reference groups

- Family

- Social class

- Culture

- Subculture

In my opinion, the most important sociocultural influence for Apple is social class. I believe this because everyone, regardless of culture or religion, makes decisions based on income. Social class can be further broken down into three general categories: 


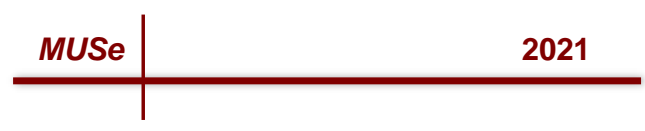

- Upper class

- Middle class

- Lower class

In 2017 "about half (52\%) of American adults lived in the middle-class," which is greater than the $48 \%$ in the upper and lower classes, 19\% and 29\%, respectively (Kochhar, 2020, para. 1). Thus, I believe that Apple should prioritize marketing practices towards the middle class. Based on the price comparison to other well-known brands like Samsung and Huawei, I gauge that Apple targets the upper/middle class and not the middle class (see Table 1). By charging significantly more than its competitors but competing in the same market, Apple is losing potential profits.

Table 1. iPhone Comparison With That of Competitors

\begin{tabular}{|l|l|l|l|}
\hline Brand/Phone & Apple iPhone X & Huawei P20 Pro & Samsung Galaxy S9 \\
\hline Storage & $64 \mathrm{~GB}$ & $128 \mathrm{~GB}$ & $64 \mathrm{~GB}$ \\
\hline Ram & $3 \mathrm{~GB}$ & $6 \mathrm{~GB}$ & $4 \mathrm{~GB}$ \\
\hline Display size & $5.8 \ln (14.73 \mathrm{~cm})$ & $6.1 \ln (15.49)$ & $5.8 \ln (14.73)$ \\
\hline Price (CAD) & Approx. $\$ 1560$ & Approx. $\$ 1140$ & Approx. $\$ 1015$ \\
\hline
\end{tabular}

Adapted from "Compare Apple iPhone X VS Huawei P20 Pro VS Samsung Galaxy S9," Gadgets Now, 2021, https://www.gadgetsnow.com/compare-mobile-phones/Apple-iPhone-X-vs-Huawei-P20-Pro-vsSamsung-Galaxy-S9.

${ }^{*}$ Prices are based on the price at first release.

\section{Target Market/Segmentation}

The potential increase in sales and profits is what drives segmentation. Overall, segmentation is a key component of a marketing strategy, as it helps to serve the customer and increase the firm's financial position.

Geographically, I would argue that Apple iPhones are only consistently present in developed countries, which opens the opportunity to expand into developing countries, as mentioned earlier. Demographically, age and income are the driving factors for Apple. Marketing to youth and young adults increases Apple's revenues, as these target groups tend to be more impulse buyers. Youth and young adults are seen as 'tech-savvy' and willing to spend more on their wants, making the iPhone marketed to a sizable, desired, and fast-growing market (Mickalowski et al., 2008). Additionally, consumers are becoming more likely to buy Apple products with rising household income levels, as discussed earlier, as consumers have more income to spend on wants. The increase in demand will therefore be for high-end cellphone products like the new iPhone.

Secondly, I have chosen to use demographic segmentation, utilizing the market segment of income (social class) to create a product market grid for various iPhones (See Table 2). 


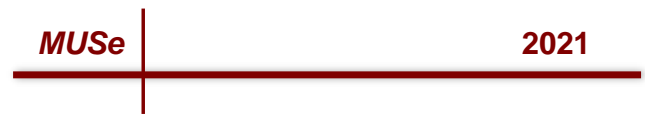

Using this data, a perceptual map has been developed which shows the position of the iPhone compared to competitor products (please refer to Figure 1).

Table 2. Product-Market Grid of iPhone

\begin{tabular}{|l|c|c|c|}
\hline \multicolumn{1}{|c|}{$\begin{array}{c}\text { Market Segments } \\
\text { (income) }\end{array}$} & \multicolumn{3}{c|}{ Apple iPhone } \\
\cline { 2 - 4 } & iPhone 12 Pro & iPhone X & iPhone SE \\
\hline Upper Class & $19 \%$ & & \\
\hline Middle & & $52 \%$ & \\
\hline Lower & & & $29 \%$ \\
\hline
\end{tabular}

Figure 1. Perceptual Map of iPhone Compared to That of Competition

Perceptual Map:

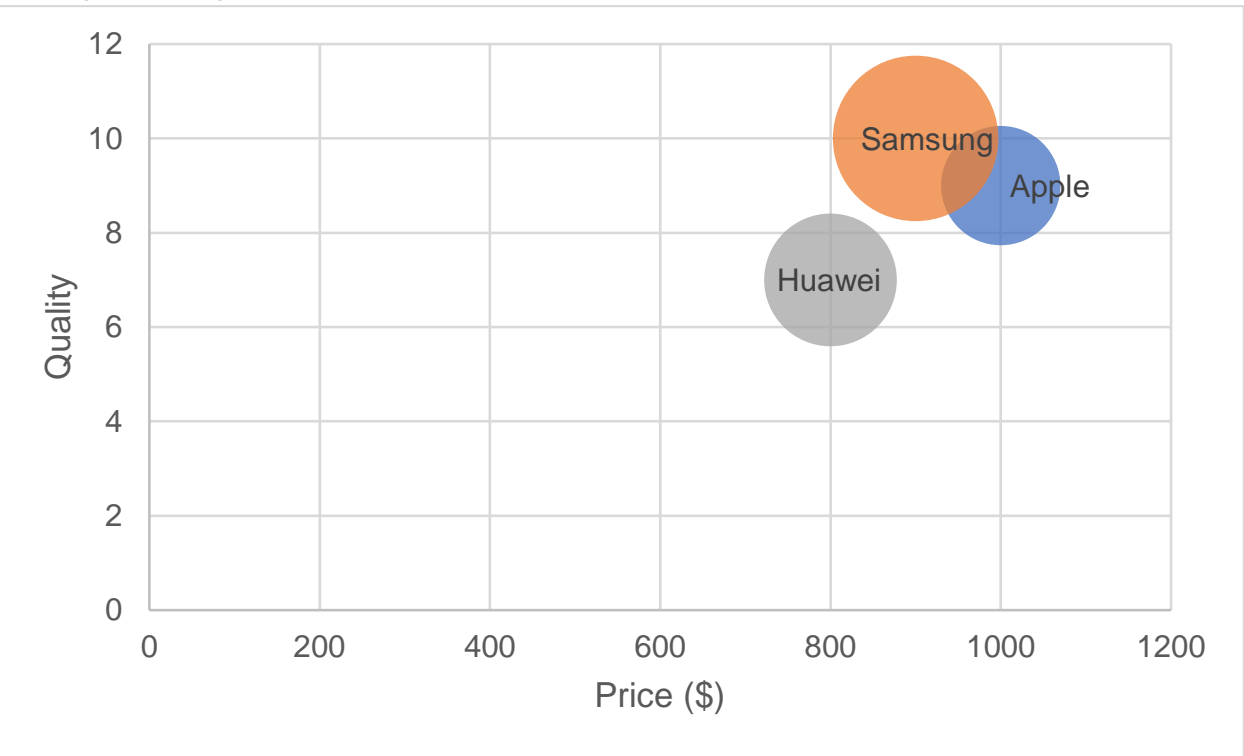

Perceptual Map Based on:

\begin{tabular}{|l|r|r|r|}
\hline & $\begin{array}{l}\text { Price } \\
\text { (avg) }\end{array}$ & Quality & $\begin{array}{l}\text { (Cell phone) } \\
\text { Market Share }\end{array}$ \\
\hline iPhone & 1000 & 9 & $12 \%$ \\
\hline Samsung & 900 & 10 & $23 \%$ \\
\hline Huawei & 800 & 7 & $15 \%$ \\
\hline
\end{tabular}

Adapted from "Smartphone Market Share," IDC, 2021, https://www.idc.com/promo/smartphone-marketshare/vendor.

I would argue that the Apple iPhone's current target market, mainly consisting of the upper-middle class, has worked and will continue to work in the company's favor as it meets the basic market segmentation criteria:

1. Have an excellent current market size.

2. Have various options for expected growth and future volumes. 


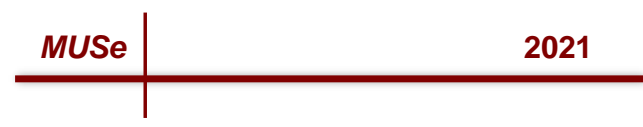

3. Hold a competitive position in price pressure (but can still be further improved, in my opinion)

4. A relatively stable cost of reaching the segment with advertising.

According to Brandon Gaille, the trend of Apple's iPhone target market demographics is: "the average age of an Apple customer is 35-44 ... men outnumber women on a 2:1 basis ... (and) one-quarter of people between 18-34 will likely purchase another apple product in the next six months" (Gaille, 2016, para. 7). In addition, Apple has been able to increase their target market by advertising the iPhone as a service rather than a product. They have done so by stressing the capabilities of the iPhone and third-party applications rather than focusing on technology alone (Laugensen \& Yuan, 2010).

\section{Recommendations}

As competition for Apple's market share over the cellphone industry is steadily on the rise, Apple needs to consider potential opportunities in the market to continue to increase phone sales. Based on the position of the iPhone compared to competition along the dimensions of quality and price, as reflected in the perceptual map (Figure 1), the following recommendations are made:

- Slightly lower the products price to target the whole middle class to improve your position in price pressure over the market. For example, a large number of consumers have spending budgets. Therefore, a key influence on the consumers' buying decision to buy an iPhone would be its price. A lower price would mean that more restricted consumers could afford the iPhone.

- Step up innovation efforts to maintain a leading edge in technology and thus, increase competitiveness against big brands like Samsung and Huawei. (Figure 1)

- Continue to improve consumer relations to increase barriers to entry. Apple should ensure that they are keeping track of what their customers value in upcoming iPhones. By incorporating user feedback, they can continue to satisfy consumers.

- Prepare clear-cut marketing plans to ensure early action on upcoming opportunities like the rapid increase in demand for iPhones in developing countries. This will ensure that Apple acts on the trend before leading competitors.

- Identify the threats and pursue the opportunities of current and future buyer and supplier power. As suppliers increase and there are many cheaper sources of raw materials in global supply chains for making iPhones, Apple should take advantage of these lower costs and build volumes through efficiencies in global supply chain management in order to raise profits.

- Continue to look for upcoming trends in product usage and technology trends and incorporate them into new products. Ensure that competitors do not advance past Apple in terms of technology offered in their products. By staying up to date on technological trends and innovation, Apple should not have to worry about being surpassed by competition. 


\section{Conclusion}

It is irrefutable to say that Apple Inc. is one of the most well-known companies to date. With a huge brand name and consumer base, Apple has been able to target multiple markets simultaneously. The Apple iPhone has successfully been able to satisfy the need for a portable, yet powerful device, that allows the user to access information quickly and efficiently. First, an environmental scan helped us see some upcoming opportunities and threats for Apple Inc., such as developing countries' growth. Second, by defining Apple's main consumer behaviours in terms of psychological and sociocultural influences, we can see that Apple products give consumers an idealized view of themselves and a sense of luxury. Third, by identifying Apple's target market for the iPhone and using a market-product grid and perceptual map, we can determine Apple's ideal market is towards men between the ages 35-44 and secondary market to ages 18-34. Along with Apple's brand name, its successful influence on its target market has led them to become the technology giant they are today. 


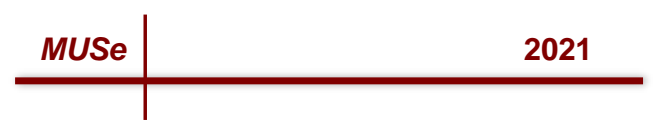

\section{References}

Atkinson, J. (2018). Consumer psychology - Groups influence buying. Persuasionworks. http://www.persuasionworks.com/consumer-psychology/buyer-perceptions-and-selfconcept.htm.

Dang, T. K. (2020, May 31). Is Apple planning to enter cloud computing space? Forbes. https://www.forbes.com/sites/taarinikaurdang/2020/05/31/is-apple-planning-to-entercloud-computing-space/?sh=9696a42d533f.

David, J. (2020, October 9). PESTEL analysis of Apple. How and what. https://howandwhat.net/pestel-analysis-apple/.

Dudovskiy, J. (2021, February 15). Apple organizational structure: a brief overview. BRM. https://research-methodology.net/apple-organizational-structure-a-hierarchical-structurethat-may-change-in-near-future/.

Gaille, B. (2019, November 22). 18 key Apple target market demographics. BrandonGaille. https://brandongaille.com/18-apple-target-marketdemographics/\#: :text=The\%20Trends\%20of\%20Apple's\%20Target\%20Market\%20De mographics\&text=The\%20average \%20age\%20 of\%20an,in\%20the \%20next $\% 206 \% 20 \mathrm{~m}$ onths

Gibbs, S. (2018, August 2). Apple's six defining products - in pictures. The Guardian. https://www.theguardian.com/technology/gallery/2018/aug/02/apples-six-definingproducts-in-pictures.

IDC Corporate USA. (2021, January 4) Smartphone market share - Vendor. IDC. https://www.idc.com/promo/smartphone-market-share/vendor.

Kochhar, R. (2020, May 30). The American middle class is stable in size but losing ground financially to upper-income families. Pew Research Center. https:/www.pewresearch.org/fact-tank/2018/09/06/the-american-middle-class-is-stablein-size-but-losing-ground-financially-to-upper-income-families/.

Laugesen, K. Yuan, Y. (2010). What factors contributed to the success of the apple iPhone? Sheridan. https://source.sheridancollege.ca/pilon publ/18/

Lombardo, J. (2019, June 9). Apple Inc. PESTEL/PESTLE analysis \& recommendations. Panmore Institute. http://panmore.com/apple-inc-pestel-pestle-analysisrecommendations. 
Maverick, J. B. (2021, January 16). Analyzing Porter's 5 forces on Apple (AAPL). Investopedia. https://www.investopedia.com/articles/investing/111015/analyzing-porters-five-forcesapple.asp.

Mickalowski, K. et al. (2008). Apple's iPhone launch: A case study in effective marketing. Augustana University. https://www.augie.edu/sites/default/files/u57/pdf/jaciel subdocs/iPhone.pdf

Pierce, D. (2018). The complete history of the iPhone-and what's coming next. Wired. https://www.wired.com/story/guide-iphone/.

Statista Research Department. (2021, January 22). Apple product sales till 2018. Statista. https://www.statista.com/statistics/382302/unit-sales-of-apple-by-productcategory/\#: : :text=The\%20iPhone\%20is\%20Apple's, respectively\%20in\%20the\%20same \%20quarter. 